\title{
Time and Cost Optimization Techniques in Construction Project Management
}

Mr.Bhushan $\mathrm{V}^{1}$. Tatar and Prof.Rahul S.Patil ${ }^{2}$

\begin{abstract}
In the field of Construction, the important objective of every project is to complete the scope of work on time, within the budget and the quality. Time and cost trade off are the two important factors in every construction project which are crucial in achieving the project objectives. There is always a relationship between time and cost. Optimizing the time \& cost is necessary in order to find out the optimum project duration corresponding to the minimum total cost and this can be achieved with the help of reducing the duration of critical activities in the network in order to minimize the overall project duration. Over the last several years, variety of methods for time and cost optimization was developed with the objective of minimizing the project cost and duration. However, existing methods ignored the effect of total float consumption resulting from decrease in duration with an increased in cost. Time \& Cost trade off techniques result in reducing the available total float for non-critical activities and thus reduce the schedule flexibility. Hence there is a necessity to establish a new technique for a time cost trade off that can provide optimum time and cost value for a project taking into consideration the effect of total float consumption. In this study an attempt is made in establishing the nonlinear integer programming technique using what's best solver which is applied to the practical project example related to construction of culvert in order to find out the optimum time and cost value. The hypothesis is that optimum schedule obtained will be at higher duration and cost but with lower risk. The results obtained are significant in comparison with deterministic CPM and allow the project incharge to exercise new tradeoffs between time, cost and overall flexibility. This results in improving the probability of achieving the objectives of project.
\end{abstract}

Keywords-Cost,Float,Non-linear Integer Programming,Time

\section{INTRODUCTION}

In the field of Construction the term 'project' refers as a temporary endeavour undertaken to create a new product or service to achieve specified project objectives within the assigned resources [1]. Every Construction project is having planned budget and planned schedule. The budget is a term that means the measure of the cost that the project will consume in order for the final deliverable to be finished. The project total cost is classified into direct cost and indirect cost which are the major types of cost related to construction in considering the optimization cost. Time and cost are the two important factors in construction projects. Over the last several years, critical path method has been used in the construction industry for the project scheduling and control. Critical Path method is based on the assumption that the duration and the cost of activities in project network are deterministic; accordingly, the project duration

${ }^{1}$ Department of Civil Engineering, Dr.D.Y.Patil Institute of Engineering \& Technology, Pimpri, Pune18,MH, India.

${ }^{2}$ Department of Civil Engineering, Dr.D.Y.Patil Institute of Engineering \& Technology, Pimpri, Pune18,MH, India. 
and cost with critical path method would also be deterministic. One major drawback of the deterministic CPM is that it cannot quantify the influence of within the float delays of noncritical activities on the project duration and cost [6]. The use of NLIP techniques provide decision makers more efficient tool to solve the time and cost optimization problem with minimum risks allied with the float consumption in terms of time and cost.

\section{LITERATURE SURVEY}

The time-cost optimization techniques are based on the critical path method (CPM) and have been used in the construction industry over the last several years. An important advantage of CPM is that it helps project managers to identify the activities that are critical for the timely completion of project [5].Time and cost trade off analysis usually assumes that the project duration is reduced through critical activities only and the amount of crashing time for each activity is limited. Also, TCTO analysis assumes that direct costs are linear between the crash cost and the normal cost for an activity whereas the cost of overheads that is indirect cost is constant during project duration.

One of the major objectives of construction industry is the quantification and minimization of risk associated with the construction projects. An improved model of the least-cost scheduling technique is proposed by [3]. In this model, range estimating and probabilistic scheduling is applied over the data, and then the resulting data is analyze in a statistical way to reach an optimum project cost and duration at higher confidence level.

Maximum flow-Minimal cut concept is another manual optimization method for construction schedules [4]. This method states that "in the network from start to end the maximal flow is equal to the minimum cut set capacity". This method is advancement over the earlier classical optimization techniques as it is possible to solve it through computer programm and is helpful when there are multiple critical paths with numerous interrelated activities that result in a large number of compression sets to review.

\subsection{Non linear Programming}

The important assumption of this method is that all its functions are linear. Although this assumption does not hold for all the problems. As a result the objective function of one or more constraints will have non-linear relationship among decision variables. The solution method of non-linear programming generally can be classified as either direct or indirect algorithms. Examples of direct methods are the gradient algorithms where the maximum of problem is found by following the fastest rate of increases of the objective function.

In a non-linear programming method, a function may have more than one maxima or minima values. Similarly when the function is plotted, it has more than one peak and more than one valley. Each of these is a local maximum or local minimum. A global maximum of a function is a value which is higher than all values of function. Similarly a global minimum of a function is a value which is the lowest of all values of function. If a point with zero slopes is not a maximum or minimum then it is referred as a saddle point.

\subsection{Float Allocation \& Float Ownership}

Commodity approach: Introduced by [2]. The commodity approach deals with float as a commodity that is tradable between the contractor and owner. This approach gives complete control over float, because they assume the project risk as is done in lump-sum contract. The following equation guides the negotiation between the owner and the contractor during the arrangements for change orders and during the pricing process. 
Float cost per day $=$

\subsection{Findings From Literature Review}

Total Float

The review of literature conclude that there is necessity to include the effect of float consumption in the time and cost trade off analysis to account for risks associated with the float consumption in noncritical activities in order to improve the consistency and effectiveness of the time and cost optimization process in construction projects.

\section{METHODOLOGY}

The deterministic approach is based on critical path method and has been the most widely used method in planning and controlling of the construction projects. The important objective of the critical path method implementation was to determine how best to reduce the time required to perform routine and repetitive tasks that are needed to support an organization.

Various Terms used in Time Cost Optimization

1) Normal Cost: It is the lowest cost of completing an activity in minimum time employing normal means that is not using overtime or special resources.

2) Normal Time: It is minimum time required to achieve the normal cost.

3) Crash Cost: It is a least cost of completing an activity by employing all possible means like overtime, additional machinery and proper materials.

4) Crash Time: It is an absolute minimum time associated with the crash cost.

5) Critical Path: It is the sequence of project network terminal elements with the longest overall duration, determining the shortest time to complete the project.

Following Steps are carried out while performing the time and cost optimization.

Step1. The Schedule required for completing the project is developed based on the normal duration and normal cost of activities involved.

Step2. Then it is required to find out the crash cost and crash duration for each activity. After this cost slope is obtained with the help of following formula:

Cost Slope $=($ Crash cost - Normal cost $) /($ Normal time - Crash time $)$

Step3. To identify the critical activities on the critical path, then identifying the critical activity that can be crashed with the least crashing slope. If there is more than one critical path, a critical activity from each path should be selected and crashed as long as the two selected activities can still be crashed and the total crash cost of the selected activities is the minimum.

Figure 3.1 presents the cost function of an activity including the cost slope. 


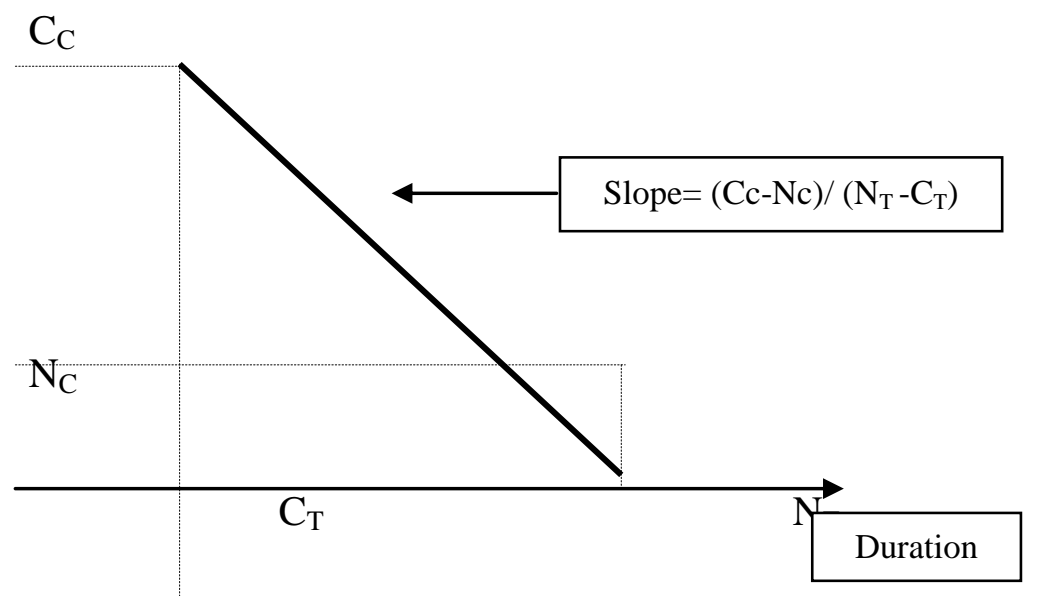

Figure 3.1: Cost function of an activity

Where,

$\mathrm{N}_{\mathrm{C}}$ : Normal Cost of an activity

$\mathrm{C}_{\mathrm{C}}$ : Crash Cost of an activity

$\mathrm{N}_{\mathrm{T}}$ : Normal duration of an activity

$\mathrm{C}_{\mathrm{T}}$ : Crash duration of an activity

Step4. Shortening the activity by the units required that is maximum crashing units is obtained by subtracting crashing time from normal time.

Step5. The new cost and duration of the project should be calculated at this step, and then steps through three to five should be repeated until the optimum solution is obtained.

\subsection{Nonlinear Integer Programming Technique}

The advantage of nonlinear integer programming technique is its flexibility and ability to solve an optimization problem with and without float consumption impact which is useful for the decision makers in order to choose the optimum solution based on the nature and circumstances of the construction projects

\subsubsection{What's Best Solver}

What's Best Solver ${ }^{\circledR}$ Version: 11.0 is added into excel and supports a variety of optimization models such as linear, integer, quadratic and nonlinear models within an excel spreadsheet. This software is useful in determining an optimal solution containing 150 constraints, 300 variables and 30 integers.

\section{ANALYSIS OF DATA}

\subsection{Deterministic Approach based on CPM}

The various activities required for the construction of culvert are listed and depending upon the availability of resources the duration for each activity is decided. And for each activity, the activity code is assigned. Table 4.1 shows the project data in terms of time and cost. The indirect cost is assumed to be Rs.300 per day.

Table 4.1: Project Crashed \& Normal duration and costs

\begin{tabular}{|c|c|c|c|c|c|c|}
\hline $\mathrm{Sr}$ & Activity Description & Activity & Normal & Normal & Crash & Crash \\
\hline
\end{tabular}




\begin{tabular}{|c|l|c|c|c|c|c|}
\hline No. & & Code & $\begin{array}{c}\text { duration } \\
\text { (days) }\end{array}$ & $\begin{array}{c}\text { Cost } \\
\text { (Rs) }\end{array}$ & $\begin{array}{c}\text { duration } \\
\text { (days) }\end{array}$ & cost (Rs) \\
\hline 1. & $\begin{array}{l}\text { Excavation work for abutments \& } \\
\text { piers }\end{array}$ & $\mathrm{A}$ & 6 & 700 & 4 & 850 \\
\hline 2. & $\begin{array}{l}\text { Foundation Concrete for Abutment \& } \\
\text { piers }\end{array}$ & $\mathrm{B}$ & 3 & 800 & 2 & 1000 \\
\hline 3. & Curing of PCC of abutment \& piers & $\mathrm{C}$ & 4 & 1000 & 4 & 1000 \\
\hline 4. & $\begin{array}{l}\text { Excavation, Foundation Concrete \& } \\
\text { Curing of PCC for wing walls }\end{array}$ & $\mathrm{D}$ & 7 & 500 & 5 & 700 \\
\hline 5. & Procurement of Rubble & $\mathrm{E}$ & 3 & 300 & 2 & 500 \\
\hline 6. & $\begin{array}{l}\text { UCR Masonry for abutment, pier \& } \\
\text { wing wall }\end{array}$ & $\mathrm{F}$ & 7 & 400 & 6 & 800 \\
\hline 7. & Earth Filling for wing walls & $\mathrm{G}$ & 3 & 100 & 2 & 200 \\
\hline 8. & Formwork for Deck Slab & $\mathrm{H}$ & 7 & 500 & 5 & 800 \\
\hline 9. & $\begin{array}{l}\text { Procuring Steel \& placing } \\
\text { reinforcement }\end{array}$ & $\mathrm{I}$ & 8 & 200 & 6 & 1100 \\
\hline 10. & Concreting \& Curing of deck slab & $\mathrm{J}$ & 10 & 350 & 7 & 600 \\
\hline 11. & $\begin{array}{l}\text { Procuring \& fixing hand rails, WBM } \\
\text { \& Surfacing }\end{array}$ & $\mathrm{K}$ & 9 & 700 & 8 & 850 \\
\hline
\end{tabular}

The results obtained over the various crashing schedules are shown in table 4.2

Table 4.2: Deterministic Approach-Total Cost after crashing

\begin{tabular}{|c|c|c|c|c|c|}
\hline Sr No & Crashing Schedule & $\begin{array}{c}\text { Project } \\
\text { Duration } \\
\text { (days) }\end{array}$ & $\begin{array}{c}\text { Direct Cost } \\
(\mathrm{Rs})\end{array}$ & $\begin{array}{c}\text { Indirect } \\
\text { Cost (Rs) }\end{array}$ & $\begin{array}{c}\text { Total Cost } \\
\text { (Rs) }\end{array}$ \\
\hline 1. & Normal Schedule & 36 & 5,550 & 10,800 & 16,350 \\
\hline 2. & First Crash Schedule & 34 & 5,700 & 10,200 & 15,900 \\
\hline 3. & Second Crash Schedule & 32 & 5,866 & 9,600 & 15,466 \\
\hline 4. & Third Crash Schedule & 31 & 6,016 & 9,300 & 15,316 \\
\hline 5. & Fourth Crash Schedule & 30 & 6,549 & 9,000 & 15,549 \\
\hline 6. & Fifth Crash Schedule & 29 & 6,949 & 8,700 & 15,649 \\
\hline
\end{tabular}

Figure 4.1 shows the time-cost tradeoff. During crashing process the direct cost starts to increase while the indirect cost decreases as it is a function of time. 


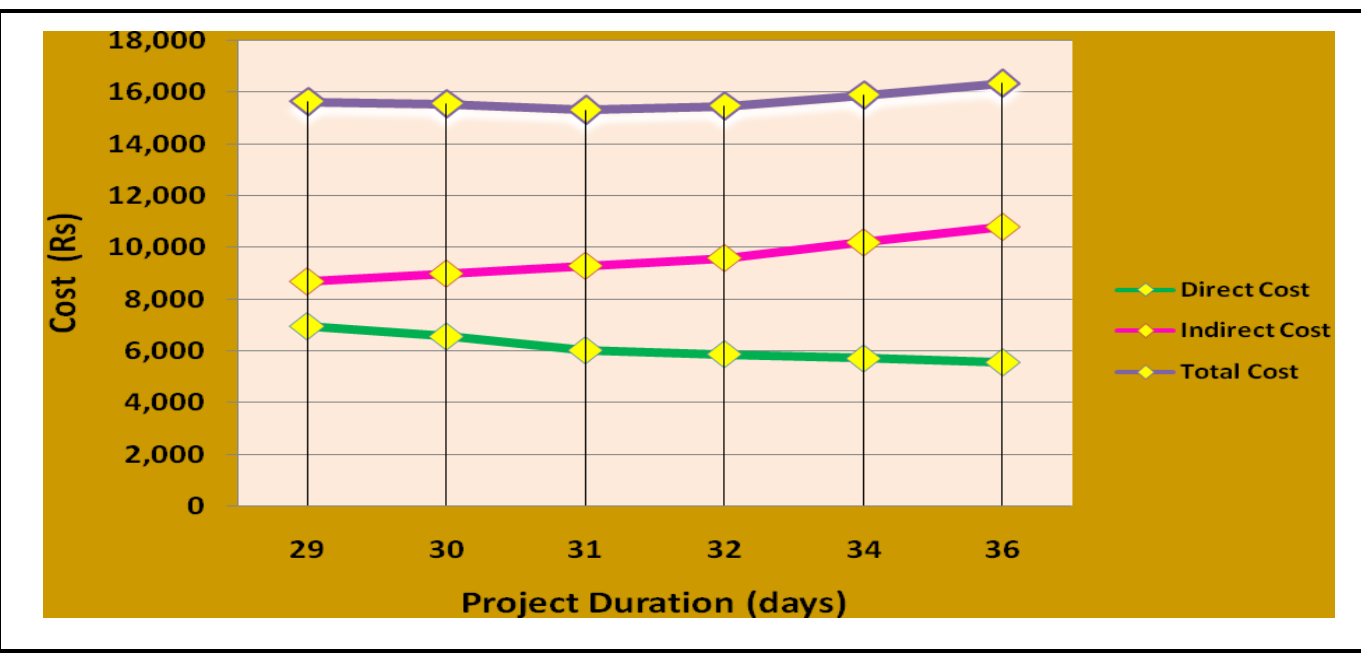

Figure 4.1: Project Time Cost Relationship

4.2 Non Linear Integer Programming Technique

Table 4.3: NLIP Technique-Total Cost after crashing

\begin{tabular}{|c|c|c|c|c|c|}
\hline Sr No & Crashing Schedule & $\begin{array}{c}\text { Project } \\
\text { Duration } \\
\text { (days) }\end{array}$ & $\begin{array}{c}\text { Direct Cost } \\
\text { (Rs) }\end{array}$ & $\begin{array}{c}\text { Indirect } \\
\text { Cost (Rs) }\end{array}$ & $\begin{array}{c}\text { Total Cost } \\
\text { (Rs) }\end{array}$ \\
\hline 1. & Normal Schedule & 36 & 5,550 & 10,800 & 16,350 \\
\hline 2. & First Crash Schedule & 34 & 5,700 & 10,200 & 15,900 \\
\hline 3. & Second Crash Schedule & 33 & 5,858 & 9,900 & 15,758 \\
\hline 4. & Third Crash Schedule & 32 & 6,008 & 9,600 & 15,608 \\
\hline 5. & Fourth Crash Schedule & 30 & 6,733 & 9,000 & 15,733 \\
\hline
\end{tabular}

Figure 4.2 shows the time-cost tradeoff. During crashing process the direct cost starts to increase while the indirect cost decreases as it is a function of time.

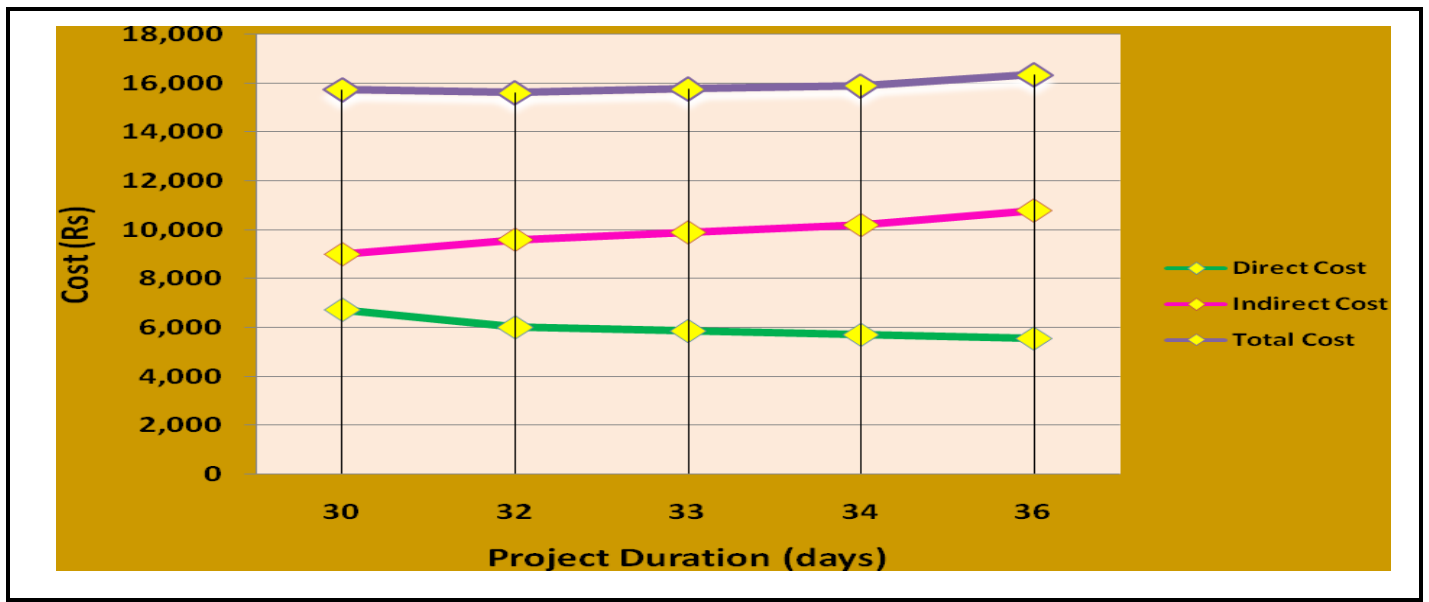

Figure 4.2: Project Time Cost Relationship 


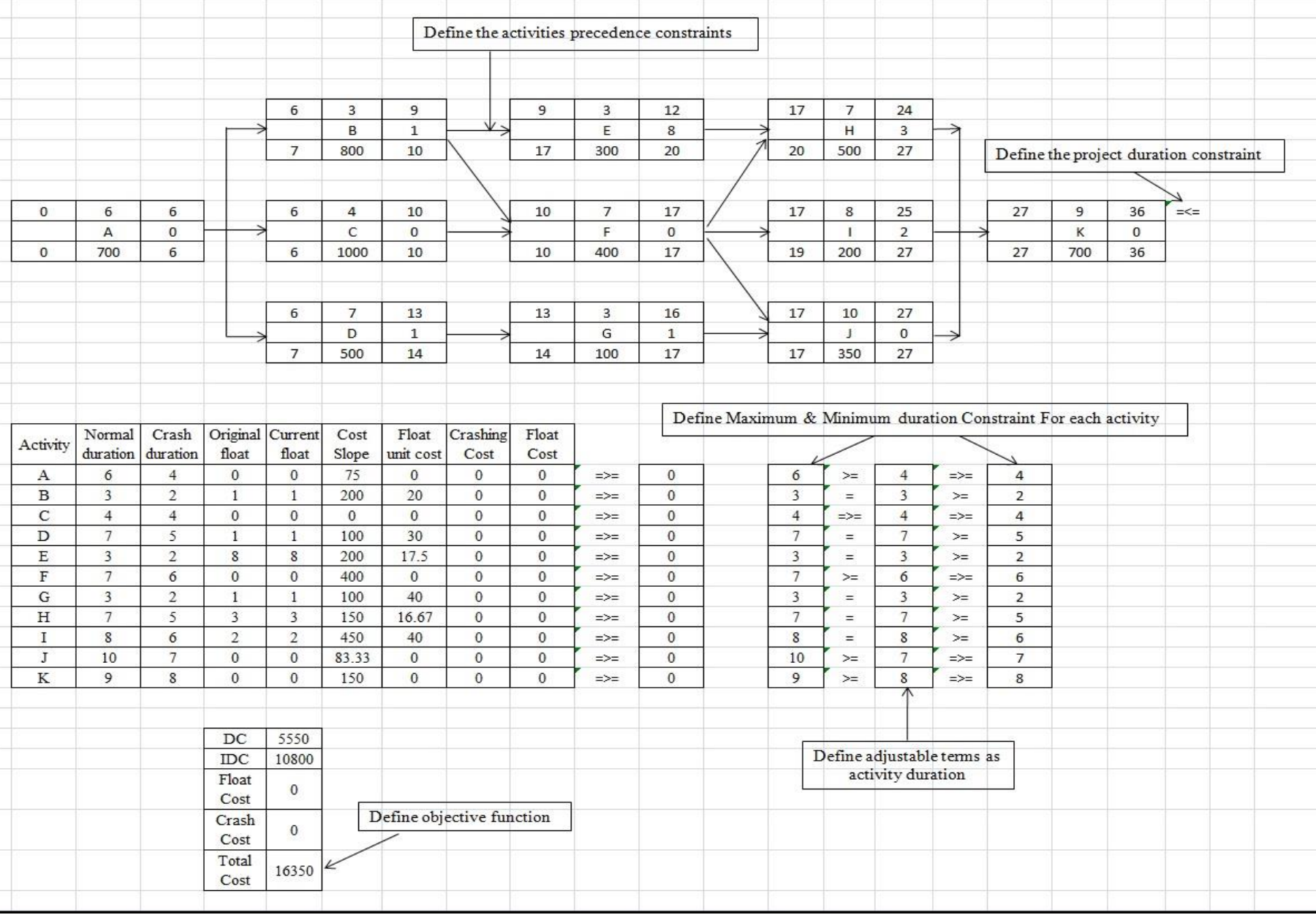

Figure 4.3: Project Example using Microsoft Excel \& What's Best Solver

\section{RESULTS \& DISCUSSIONS}

The total float available for noncritical activities in the deterministic method and the NLIP technique is presented in table 5.1

Table 5.1: TF Comparison-Deterministic method \& NLIP Technique

\begin{tabular}{|c|c|c|}
\hline $\begin{array}{c}\text { Non Critical } \\
\text { Activity }\end{array}$ & $\begin{array}{c}\text { Deterministic Method @ } \\
\text { 31 days duration }\end{array}$ & $\begin{array}{c}\text { NLIP Technique @ } \\
\text { 32 days duration }\end{array}$ \\
\hline B & 1 & 1 \\
\hline D & 1 & 1 \\
\hline E & 6 & 7 \\
\hline G & 1 & 1 \\
\hline H & 1 & 2 \\
\hline I & 0 & 1 \\
\hline
\end{tabular}


From the above table it is observed that the use of NLIP technique is better in comparison with deterministic method in terms of remaining float as it finds a competent solution that can save total float for future use with a less risky cost.

The Criticality ratio is defined as a ratio between the number of critical activities to the total number of activities. For a deterministic method without considering the effect of float consumption, the criticality ratio is calculated to be 0.545 \& by considering the float consumption impact, the criticality ratio is calculated to be 0.454 .

The probability of finishing project within 32 days when the float consumption impact is considered is $0.3752 \&$ the probability of finishing the project within 31 days when the float consumption impact is not considered is 0.3188 . The results obtained by considering the float consumption impact in comparison with deterministic approach provided a higher probability of finishing project on time, a better criticality indices and a lesser difference in the total cost which is helpful in minimizing the risks associated with the overall project flexibility.

\section{CONCLUSIONS AND FUTURE SCOPE}

The result obtained by using NLIP technique is better in comparison with deterministic approach in terms of schedule flexibility, critical index, criticality ratio \& probability of finishing. In order to decrease the calculation time and to improve the speed and overall efficiency of the two techniques, it is suggested to use the meta-heuristic techniques also called as global heuristic techniques that are used to compute the exact optimum solutions.

\section{REFERENCES}

[1]Chitkara, K, K. (2005). Construction Project Management: Planning, Scheduling, and Controlling. Tata McGraw Hill Publishing Company Ltd.

[2]De La Garza, J., Vorster, M., and Parvin, M. (1991). “Total float traded as commodity.”Journal of Construction Engineering and Management, 117(4), 716-727.

[3]Isidore, L., and Back, E. (2002). "Multiple simulation analysis for probabilistic cost and schedule integration." Journal of Construction Engineering and Management, 128(3), 211-219.

[4]Liu, J., and Rahbar, F. (2004). "Project time-cost tradeoff optimization by maximal flow theory." Journal of Construction Engineering and Management, 130(4), 607-609.

[5]Moussourakis, J., and Haksever, C. (2007). "Models for accurate computation of earliest and latest start times and optimal compression in project networks." Journal of Construction Engineering and Management, 133(8), 600-608.

[6]Sakka, Z., and El-Sayegh, S. (2007). "Float consumption impact on cost and schedule in the construction industry." Journal of Construction Engineering and Management, 133(2), 124-130. 